\title{
Extratos vegetais como alternativas aos antimicrobianos promotores de crescimento para leitões recém-desmamados 1
}

\author{
Leandro Batista Costa ${ }^{2}$, Marcos Livio Panhoza Tse ${ }^{2}$, Valdomiro Shigueru Miyada ${ }^{3}$ \\ 1 Parte da dissertação de Mestrado do primeiro autor apresentada ao Programa de Pós-graduação em Ciência Animal e Pastagens - Depto. \\ de Zootecnia, ESALQ/USP. \\ 2 Programa de Pós-graduação em Ciência Animal e Pastagens - Depto. de Zootecnia, ESALQ/USP, CEP: 13418-900, Piracicaba/SP. \\ ${ }^{3}$ Depto. de Zootecnia, ESALQ/USP, CEP:13418-900, Piracicaba/SP.
}

RESUMO - Avaliou-se, por meio do desempenho e da morfometria de órgãos, o uso de extratos vegetais como alternativas aos antimicrobianos promotores de crescimento para leitões recém-desmamados. Um experimento em blocos casualizados, com 35 dias de duração, foi realizado para testar cinco tratamentos: ração basal; antimicrobiano - ração basal com colistina + tiamulina (75 ppm de cada); extratos vegetais - ração basal com 420 ppm de cravo (Ec); orégano (Eo) e cravo + orégano $(\mathrm{Ec}+\mathrm{Eo})$, respectivamente. Os extratos continham óleo essencial de cravo + eugenol e orégano + carvacrol. Para análise do desempenho, foram utilizados 80 leitões, oito repetições por tratamento e dois animais por unidade experimental. Ao final do período experimental, um animal de cada baia, dos quatro primeiros blocos, foi abatido para avaliação da morfometria de órgãos. Foram testados contrastes específicos de importância prática. No período de 24 a 38 dias de idade, os animais do tratamento antimicrobiano apresentaram melhor conversão alimentar (CA) em comparação àqueles dos tratamentos com extratos. Os animais do tratamento com cravo $(\mathrm{Ec})$ tiveram melhor $\mathrm{CA}$ em comparação àqueles do tratamento com orégano (Eo). No período total, os animais do tratamento antimicrobiano apresentaram maior peso aos 59 dias de idade (P59) e ganho diário de peso (GDP) em relação à média dos animais dos tratamentos com extratos. Os animais do tratamento Ec + Eo apresentaram maior P59 e GDP em relação à média dos outros tratamentos com extratos. Para a morfometria de órgãos, os antimicrobianos proporcionaram maior peso relativo dos rins em relação à média dos outros tratamentos com extratos vegetais. De modo geral, os antimicrobianos proporcionaram os melhores desempenhos dos leitões em fase de creche. Quanto aos extratos vegetais, a combinação de Ec+Eo acarretou desempenho muito próximo ao obtido com os antimicrobianos, demonstrando ser uma alternativa promissora como promotor de crescimento de leitões recém-desmamados.

Palavras-chave: aditivos, desempenho, morfometria, nutrição, óleos essenciais, suínos

\section{Herbal extracts as alternatives to antimicrobial growth promoters for weanling pigs}

\begin{abstract}
The purpose of this study was to evaluate herbal extracts as alternatives to antimicrobial growth promoters for weanling pigs based on growth performance and organ weights. A 35-d randomized complete block design experiment was carried out to compare five treatments: control (C) - basal diet; antimicrobial (A) - basal diet supplemented with colistin + tiamulin (75 ppm of each); herbal extract - basal diet supplemented with $420 \mathrm{ppm}$ of extracts of clove (Ec); oregano (Eo) and clove + oregano $(\mathrm{Ec}+\mathrm{Eo})$, respectively. Herbal extracts consisted of essential oils of clove + eugenol and oregano + carvacrol. Eighty pigs sorted in eight replications per treatment, and two animals per experimental unit were used for growth performance evaluation. At the end of experimental period, one animal per pen from the first four blocks was slaughtered for organ morphometry evaluation. Specific contrasts of practical importance were tested. For 1-14 d of experimental period (24 to 38 days of age), pigs fed the antimicrobial supplemented diet showed better feed conversion rate (CA) than the mean of those fed herbal extract treatments, while pigs fed Ec supplemented diet had better CA than those fed Eo. For the total period (24 to 59 days of age), pigs fed antimicrobial showed higher body weight at 59 days of age (P59) and average daily gain (GDP) than the mean of those fed herbal extracts. Pigs fed Ec + Eo had higher P59 and GDP than the mean of those fed other herbal extract treatments. For the organ morphometry data, the antimicrobials provided a higher relative weight of kidneys compared to the mean of treatments with herbal extracts. Overall, antimicrobial agents provided the best growth performance of weanling pigs. Concerning to herbal extracts, the combination of clove and oregano provided growth performance close to that of pigs fed antimicrobials, showing that this combination can be a potential alternative as growth promoter for weanling pigs.
\end{abstract}

Key Words: additives, essential oil, growth performance, morphometry, nutrition, swine 


\section{Introdução}

A demanda de alimentos para atender às necessidades da população mundial requer produção intensiva de proteína de origem animal e das demais fontes de nutrientes, respeitando cada vez mais as questões sociais, a segurança alimentar e o meio ambiente. Nesse contexto, a produção de carne suína, que corresponde a $38,5 \%$ da produção mundial de carne (FAO, 2005), continuará a demandar grande desenvolvimento tecnológico para transformar a menor quantidade possível de grãos e de outros alimentos em proteína de excelente qualidade (Lima, 1999). Com o desenvolvimento científico, uma das técnicas utilizadas na produção animal e com resultados significativos é o uso de aditivos nas dietas para melhorar os índices zootécnicos e maximizar a produção.

Por várias décadas, os antimicrobianos (antibióticos e quimioterápicos) promotores de crescimento têm sido utilizados em dietas para suínos recém-desmamados e em crescimento no intuito de diminuir a incidência de diarréia pós-desmame e promover melhora no desempenho animal (Partanen, 2002). Nesta década, o uso desses aditivos antimicrobianos passou a ser visto como fator de risco para a saúde humana, principalmente em decorrência de duas contestações: a presença de resíduos dos antimicrobianos na carne, nos ovos e no leite e a indução de resistência cruzada para bactérias patógenas para humanos (Menten, 2001). Com isso, surgiram restrições e novas regulamentações quanto ao uso de antibióticos e quimioterápicos na alimentação animal. Na União Européia, por exemplo, a partir de janeiro de 2006 foi banido o uso de qualquer antimicrobiano promotor de crescimento na produção animal (Brugalli, 2003), sendo permitido o uso de antibióticos e quimioterápicos somente com finalidade curativa. Portanto, é necessário buscar alternativas para minimizar o impacto da retirada dos antimicrobianos como promotores de crescimento de suínos. As alternativas incluem os probióticos, os prebióticos, os ácidos orgânicos, as enzimas e os extratos vegetais.

A propriedade antiséptica das plantas medicinais e aromáticas e de seus extratos tem sido observada desde a antiguidade, enquanto as informações sobre as tentativas de caracterizar suas propriedades em laboratório datam de 1900. Com o passar do tempo, o conhecimento sobre as plantas evoluiu como consequiência, em grande parte, das modernas tecnologias, ocasionando o isolamento sistemático e a caracterização dos princípios ativos contidos nestas fontes vegetais.

Pesquisas têm focado os efeitos benéficos específicos da inclusão desses microingredientes nas rações. Essas substâncias apresentam atividade antioxidante (Botsoglou et al., 2002) de modificação da microbiota intestinal, de melhora na digestibilidade e na absorção dos nutrientes, de modificações morfo-histológicas do trato gastrintestinal e de melhora da resposta imune (Brugalli, 2003). Entretanto, ainda não está claro o modo de ação desses aditivos, que podem ter múltiplas funções. A elucidação do modo de ação destas substâncias fornecerá a base científica para se estabelecer, com eficácia e segurança, seu modo de uso em dietas para animais (Brugalli, 2003). São vários os efeitos observados in vitro que justificam as pesquisas nesta área para determinação das melhores combinações e dos níveis de inclusão dos extratos vegetais às dietas para melhorar o desempenho e a produção animal (Hernández et al., 2004).

Em condições brasileiras, são poucas as pesquisas que comprovam a ação dos extratos vegetais como promotores de crescimento de suínos. Os resultados são bastante controversos e pouco conclusivos. Esse trabalho foi realizado com o objetivo de comparar, por meio do desempenho e da morfometria de órgãos dos animais, o efeito de extratos vegetais como alternativas aos antimicrobianos promotores de crescimento para leitões recém-desmamados.

\section{Material e Métodos}

Foram utilizados 80 leitões híbridos comerciais com 24 dias de idade, em média, e pesos inicial e final de 7,19 $\pm 1,55$ e $18,73 \pm 1,84 \mathrm{~kg}$, respectivamente. Os animais foram distribuídos em um delineamento em blocos casualizados, com cinco tratamentos, oito repetições por tratamento e dois animais por unidade experimental (um macho castrado e uma fêmea).

Os tratamentos foram classificados como: controle (C) = dieta basal; antimicrobiano (A) = dieta basal com $75 \mathrm{ppm}$ de colistina $+75 \mathrm{ppm}$ de tiamulina; extrato de cravo $(E c)=$ dieta basal com 420 ppm de extrato de cravo microencapsulado (210 ppm de óleo essencial de cravo + 210 ppm do princípio ativo eugenol); extrato de orégano $($ Eo $)=$ dieta basal com $420 \mathrm{ppm}$ de extrato de orégano microencapsulado (210 ppm de óleo essencial de orégano +210 ppm do princípio ativo carvacrol); e extrato de cravo + extrato de orégano $(\mathrm{Ec}+\mathrm{Eo})=$ dieta basal com $420 \mathrm{ppm}$ de extrato de cravo + extrato de orégano microencapsulados (105 ppm de óleo essencial de cravo + 105 ppm do princípio ativo eugenol e $105 \mathrm{ppm}$ de óleo essencial de orégano + $105 \mathrm{ppm}$ do princípio ativo carvacrol). Os extratos vegetais, na forma de óleos essenciais, passaram por um processo de microencapsulamento desenvolvido pela Givaudan do Brasil Ltda., empresa especializada na extração de óleos essenciais. 
Durante o experimento, foram fornecidas duas dietas basais: a pré-inicial, dos 24 aos 38 dias de idade e a inicial, dos 39 aos 59 dias de idade. As dietas foram formuladas segundo exigências nutricionais descritas por Rostagno et al. (2005) (Tabela 1).

Durante o período experimental, os animais receberam água e alimento à vontade. As características de desempenho (consumo diário de ração, ganho diário de peso e conversão alimentar) foram calculadas por meio de pesagens dos animais no início e ao final de cada fase e pela quantificação da dieta fornecida e desperdiçada. Para análise dos dados de desempenho, foram consideradas oito repetições (blocos) por tratamento.

Ao final do período experimental (59 dias de idade), após jejum de 15 horas, foram abatidos 20 animais (um animal por unidade experimental, dos quatro primeiros blocos), para a coleta dos dados de morfometria. A escolha do animal a ser abatido foi feita considerando seu peso vivo mais próximo da média dos animais de cada bloco, independentemente do sexo. Esse critério foi adotado admitindo-se haver pouca diferença entre sexo nessa fase a ponto de comprometer os resultados de morfometria. Portanto, para análise dos dados de morfometria de órgãos, foram consideradas quatro repetições (blocos) por tratamento.

Dos animais abatidos, foram retirados e pesados os órgãos digestórios (estômago vazio, pâncreas, fígado, vesícula biliar, intestino delgado vazio, intestino grosso vazio, ceco vazio e cólon vazio) e os não-digestórios (pulmões, coração, rins e baço). Também foi medido o comprimento do intestino delgado dos animais.

Os dados foram analisados pelo SAS LAB para verificação da adequação dos dados ao modelo linear. Posteriormente, foi feita análise de variância pelo PROC GLM (General Linear Models) do SAS (2001). Foram testados contrastes específicos de maior interesse para aplicação prática.

Tabela 1 - Composição percentual e calculada das dietas basais

Table 1 - Percentage composition and calculated values of nutrients of basal diets

\begin{tabular}{|c|c|c|}
\hline $\begin{array}{l}\text { Ingrediente }(\%) \\
\text { Ingredient }\end{array}$ & $\begin{array}{l}\text { Pré-inicial } \\
\text { Pre-initial }\end{array}$ & $\begin{array}{r}\text { Inicial } \\
\text { Initial }\end{array}$ \\
\hline Milho (Corn) & 53,17 & 65,92 \\
\hline Farelo de soja $46 \%$ (Soybean meal) & 21,00 & 21,83 \\
\hline Produto lácteo ${ }^{1} 38,5 \%$ lactose (Milk product $38.5 \%$ lactose) & 2,40 & 0,00 \\
\hline Produto lácteo ${ }^{2} 70 \%$ lactose (Milk product $70 \%$ lactose) & 11,60 & 5,70 \\
\hline Lactose (Lactose) & 3,00 & 1,00 \\
\hline Plasma sangüíneo ${ }^{3}$ (Plasma) & 4,50 & 2,00 \\
\hline Fosfato bicálcico (Dicalcium phosphate) & 1,60 & 1,43 \\
\hline Calcário (Limestone) & 0,83 & 0,74 \\
\hline Óleo de soja (Soybean oil) & 1,00 & 0,50 \\
\hline L-lisina. $\mathrm{HCl} 78 \%$ (L-lysine. $\mathrm{HCl})$ & 0,20 & 0,05 \\
\hline DL-metionina $99 \%$ (DL-methionine) & 0,07 & 0,02 \\
\hline Premix mineral (Mineral premix) ${ }^{4}$ & 0,10 & 0,10 \\
\hline Premix vitamínico $\left(\right.$ Vitamin premix) ${ }^{5}$ & 0,10 & 0,10 \\
\hline Sal (Salt) & 0,22 & 0,40 \\
\hline Inerte e/ou promotor do crescimento (Inert and/or growth promoter) & 0,21 & 0,21 \\
\hline Total & 100,00 & 100,00 \\
\hline
\end{tabular}

Valores calculados 6

Calculated values

\begin{tabular}{|c|c|c|}
\hline $\mathrm{EM}(M E), \mathrm{kcal} / \mathrm{kg}$ & 3.335 & 3.240 \\
\hline $\mathrm{PB}(C P), \%$ & 21,00 & 18,00 \\
\hline Lisina total (Total lysine), \% & 1,47 & 1,05 \\
\hline Lisina digestível (Digestible lysine), \% & 1,32 & 0,99 \\
\hline Treonina digestível (Digestible threonine), \% & 0,83 & 0,71 \\
\hline Triptofano digestível (Digestible tryptophan), \% & 0,25 & 0,22 \\
\hline Metionina digestível (Digestible methionine), \% & 0,37 & 0,31 \\
\hline Metionina + cistina digestíveis (Digestible Met + Cys), $\%$ & 0,73 & 0,62 \\
\hline Lactose (Lactose), \% & 12,04 & 4,99 \\
\hline $\mathrm{Ca}, \%$ & 0,82 & 0,72 \\
\hline $\mathrm{P}$ total (Total P), \% & 0,64 & 0,60 \\
\hline P disponível (Available P), \% & 0,45 & 0,40 \\
\hline
\end{tabular}




\section{Resultados e Discussão}

No período experimental dos 24 aos 38 dias de idade, o P38, o CDR e o GDP dos leitões não foram influenciados $(\mathrm{P}>0,05)$ pelos tratamentos (Tabela 2), embora os melhores resultados numéricos tenham sido observados nos animais do tratamento antimicrobiano. Os leitões do tratamento antimicrobiano apresentaram melhor CA em comparação à média dos animais dos tratamentos com extratos vegetais $(\mathrm{P}<0,02)$. Em média, os antimicrobianos podem melhorar em $6,9 \%$ a CA nos leitões em fase de creche, quando comparados aos do tratamento controle (Hays, 1977; Zimmerman, 1986, citados por Miller et al., 1991), evidenciando melhor absorção dos nutrientes e menor gasto de energia e proteína para manutenção do trato gastrintestinal (Utiyama et al., 2006).

Os leitões do tratamento extrato de cravo apresentaram melhores resultados de $\mathrm{CA}(\mathrm{P}<0,03)$ em comparação aos do tratamento extrato de orégano. $\mathrm{O}$ extrato de cravo pode, possivelmente, ter estimulado a atividade de enzimas (amilase, proteases e lipase) e a secreção de suco pancreático e sais biliares (Sambaiah \& Srinivasan, 1991; Platel \& Srinivasan, 1996; Wang \& Bourne, 1998), pois este tratamento proporcionou, numericamente, maior peso relativo do pâncreas $(0,23$ vs 0,20$)$ e do fígado $(2,56$ vs 2,49$)$.

No período experimental dos 24 aos 38 dias de idade, o tratamento com extrato de orégano, em relação ao controle, proporcionou aos leitões resultados de P38, CDR, GDP e CA ligeiramente inferiores, apesar de não-significativos. Botsoglou et al. (2002), estudando dois níveis de óleo essencial de orégano adicionados à dieta de frangos de corte (50 e 100 mg/kg da ração), não notaram melhora no desempenho dos animais, em comparação aos alimentados com a dieta controle. O menor nível ( $50 \mathrm{mg} / \mathrm{kg}$ da ração) proporcionou, numericamente, peso vivo aos 14, 21, 28, 35 e 38 dias inferior ao obtido com o tratamento controle. Segundo esses autores, uma vez que o orégano possui ação antimicrobiana e antifúngica, era previsível uma melhora no desempenho dos frangos que receberam óleo essencial de orégano na dieta, em relação àqueles alimentados com a dieta isenta de promotor de crescimento. Segundo Zuanon et al. (1998) e Lima (1999), a ação antimicrobiana dos extratos vegetais sobre a microbiota intestinal pode controlar ou inibir o crescimento dos patógenos e, conseqüentemente, proporcionar crescimento dos microrganismos benéficos, favorecendo o desempenho animal.

Em outros experimentos com coelhos (Botsoglou et al., 2004), frangos (Botsoglou et al., 2002; Hernández et al., 2004) e suínos (Hermann et al., 2003; Utiyama et al., 2006), também não foi possível observar diferença significativa no desempenho dos animais que receberam extratos vegetais em diferentes combinações e níveis em relação a uma dieta isenta de qualquer promotor de crescimento. Dietas altamente digestíveis limitam o desenvolvimento de bactérias no trato intestinal pela redução de substrato disponível ao crescimento bacteriano, diminuindo, assim, o potencial antimicrobiano dos extratos vegetais. $\mathrm{O}$ mesmo pode ocorrer se os animais forem alojados em instalações com baixo desafio imunológico e rigoroso controle sanitário (Oetting et al., 2006), como neste experimento, no qual as instalações foram previamente desinfectadas, fechadas e mantidas vazias por 60 dias.

No período experimental dos 24 aos 59 dias de idade, os leitões do tratamento antimicrobiano apresentaram melhores resultados de $\mathrm{P} 59(\mathrm{P}<0,05)$ e $\mathrm{GDP}(\mathrm{P}<0,06)$ que a média dos leitões que receberam os diferentes tratamentos (Tabela 3). Oetting et al. (2006), estudando agentes antimicrobianos e níveis de extratos vegetais em dietas para leitões recém-desmamados, também observaram aumentos significativos no P35, P59, CDR e GDP dos animais que

Tabela 2 - Médias de peso vivo inicial aos 24 dias de idade (P24), peso vivo aos 38 dias de idade (P38), consumo diário de ração (CDR), ganho diário de peso (GDP) e conversão alimentar (CA) de leitões no período de 24 a 38 dias de idade

Table 2 - Average initial body weight at 24 days of age (BW24), body weight at 38 days of age (BW38), daily feed intake (DFI), average daily gain (ADG) and feed conversion (FC) of weanling pigs from 24 to 38 days of age

\begin{tabular}{|c|c|c|c|c|c|c|c|}
\hline \multirow{3}{*}{$\begin{array}{l}\text { Característica de desempenho } \\
\text { Growth performance characteristics }\end{array}$} & \multirow{2}{*}{\multicolumn{5}{|c|}{$\begin{array}{l}\text { Tratamento } \\
\text { Treatment }\end{array}$}} & \multirow[b]{3}{*}{$\operatorname{Pr}>\mathrm{F}$} & \multirow[b]{3}{*}{$\mathrm{CV}^{3}(\%)$} \\
\hline & & & & & & & \\
\hline & C (control) & A & $\mathrm{Ec}$ & Eo & $\mathrm{Ec}+\mathrm{Eo}$ & & \\
\hline P24 (BW24) (kg) & 7,09 & 7,11 & 7,10 & 7,21 & 7,12 & - & - \\
\hline P38 (BW38) (kg) & 9,28 & 9,74 & 9,20 & 9,13 & 9,30 & 0,56 & 7,73 \\
\hline CDR (g/dia) (DFI, g/day) & 269 & 301 & 261 & 268 & 297 & 0,76 & 22,56 \\
\hline $\operatorname{GDP}(\mathrm{g} / \mathrm{dia})(A D G, \mathrm{~g} /$ day $)$ & 156 & 198 & 151 & 137 & 156 & 0,50 & 34,68 \\
\hline $\mathrm{CA}^{2}(F C)$ & 1,87 & 1,55 & 1,79 & 2,30 & 2,11 & 0,04 & 23,21 \\
\hline
\end{tabular}

${ }^{1} \mathrm{C}$ - controle (control), A - antimicrobiano (antimicrobial), Ec - $420 \mathrm{ppm}$ de extrato de cravo (420 ppm of clove extract), Eo - 420 ppm de extrato de orégano (420 ppm of oregano extract), Ec + Eo - 420 ppm de extrato de cravo + extrato de orégano (420 ppm of clove and oregano extracts).

2 Contrastes significativos: (1) A X média de Ec, Eo, Ec + Eo $(P<0,02)$ e $(2) E c X$ Eo $(P<0,03)$.

2 Contrasts significantly different: (1) AX mean of $E c, E O, E C+E O(P<.02)$ and (2) $E_{C} X E_{O}(P<.03)$.

3 Coeficiente de variação (Coefficient of variation). 
Tabela 3 - Médias de peso vivo inicial aos 24 dias de idade (P24), peso vivo aos 59 dias de idade (P59), consumo diário de ração (CDR), ganho diário de peso (GDP) e conversão alimentar (CA) de leitões no período de 24 a 59 dias de idade

Table 3 - Average initial body weight at 24 days of age (BW24), body weight at 59 days of age (BW59), daily feed intake (DFI), average daily gain (ADG) and feed conversion (FC) of weanling pigs from 24 to 59 days of age

Característica de desempenho

Growth performance characteristics

$\mathrm{P} 24(B W 24)(\mathrm{kg})$

P5 $9^{2}(B W 59)(\mathrm{kg})$

$\mathrm{CDR}(\mathrm{g} / \mathrm{dia})(D F I$, g/day)

$\mathrm{GDP}^{3}(\mathrm{~g} / \mathrm{dia})(A D G$, g/day $)$

$\mathrm{CA}(F C)$

Tratamento ${ }^{1}$

Treatment

\begin{tabular}{|c|c|c|c|c|c|c|}
\hline C (control) & A & Ec & Eo & $\mathrm{Ec}+\mathrm{Eo}$ & $\operatorname{Pr}>\mathrm{F}$ & $\mathrm{CV}^{4}(\%)$ \\
\hline 7,09 & 7,11 & 7,10 & 7,21 & 7,12 & - & - \\
\hline 18,81 & 19,72 & 17,30 & 17,62 & 19,41 & 0,06 & 9,83 \\
\hline 498 & 533 & 449 & 480 & 528 & 0,25 & 16,05 \\
\hline 334 & 361 & 291 & 298 & 353 & 0,06 & 16,47 \\
\hline 1,55 & 1,52 & 1,72 & 1,68 & 1,60 & 0,41 & 14,06 \\
\hline
\end{tabular}

${ }^{1} \mathrm{C}$ - controle (control), A - antimicrobiano (antimicrobial), Ec - $420 \mathrm{ppm}$ de extrato de cravo (420 ppm of clove extract), Eo - 420 ppm de extrato de orégano (420 ppm of oregano extract), Ec + Eo - 420 ppm de extrato de cravo + extrato de orégano (420 ppm of clove and oregano extracts).

2 Contrastes significativos (P59): (1) A X média de Ec, Eo e Ec + Eo $(P<0,05)$ e $(2)$ média de $E c$ e $E o X E c+E o(P<0,02)$

2 Contrasts significantly different (P59): (1) AX mean of $E c$, EO and $E C+E O(P<05)$ and (2) mean of $E c$ and $E_{O} X E_{C}+E_{O}(P<.02)$.

${ }^{3}$ Contrastes significativos (GDP): (1) A X média de Ec, Eo e $E c+E o(P<0,06)$ e (2) média de $E c$ e Eo $X E c+E o(P<0,02)$.

${ }^{3}$ Contrasts significantly different (GDP): (1) $A X$ mean of $E c$, Eo and $E c+E O(P<.06)$ and $(2)$ mean of $E c$ and $E O X E C+E O(P<.02)$.

4 Coeficiente de variação (Coefficient of variation).

receberam antimicrobianos na dieta em relação àqueles dos tratamentos controle e com extratos vegetais. Os antimicrobianos, em virtude de seu mecanismo de ação (Jong et al., 1985) promovem alteração da população microbiana do intestino animal e propiciam o crescimento das bactérias benéficas (Zuanon et al., 1998; Lima, 1999). Essas substâncias agem sobre as bactérias e/ou fungos sensíveis, promovendo a morte do agente (efeito bactericida) ou interrompendo seu crescimento e sua reprodução (efeito bacteriostático). Esses efeitos podem ocorrer na síntese da parede celular dos microrganismos, proporcionando alterações na permeabilidade da membrana citoplasmática, interferências na replicação cromossômica e na síntese protéica celular (Tavares, 1990; Mellor, 2000). Podem, também, promover economia de nutrientes, controlar doenças subclínicas e atuar sobre o metabolismo animal (Menten, 1995), acarretando melhor eficiência na utilização do alimento e, conseqüentemente, melhor desempenho.

Os leitões do tratamento composto da mistura de extrato de cravo + extrato de orégano também apresentaram melhores resultados de $\mathrm{P} 59(\mathrm{P}<0,02)$ e GDP $(\mathrm{P}<0,02)$ em relação à média dos leitões dos tratamentos individuais de extrato de cravo ou extrato de orégano. A combinação de extratos vegetais proporcionou os resultados mais próximos daqueles obtidos com os antimicrobianos durante todo o período experimental. Por outro lado, não foi detectada qualquer diferença na $\mathrm{CA}$ dos animais entre os tratamentos $(P>0,05)$. Lee et al. (2003), estudando o efeito do timol (princípio ativo do tomilho), do cinamaldeído (princípio ativo da canela) e de uma mistura comercial de óleos essenciais em dietas para frangos de corte, observaram melhora numérica no desempenho dos animais que rece- beram a mistura comercial em comparação aos dos demais tratamentos.

Alguns extratos vegetais têm alto poder antimicrobiano sobre diversos patógenos. Para que este efeito seja observado in vivo, os níveis de inclusão na dieta devem ser elevados ou esses extratos devem ser suplementados em combinações com diferentes extratos, cujos diferentes componentes que se completam e reforçam sua ação sobre o organismo (Oetting et al., 2006). Além disso, pesquisas recentes têm demonstrado a existência de um efeito sinérgico entre componentes primários e secundários das plantas, observando-se que os componentes secundários atuam como potencializadores dos componentes primários (Kamel, 2000), o que, possivelmente, explica os melhores resultados, neste trabalho, da combinação extrato de cravo + extrato de orégano em relação aos tratamentos extrato de cravo e extrato de orégano, adicionados individualmente às dietas experimentais.

Considerando que os resultados encontrados na literatura são inconsistentes e contraditórios e que são poucos os trabalhos realizados com extratos vegetais, vários estudos são necessários para determinação da possível eficácia, dos níveis ideais de inclusão e das melhores combinações dessas substâncias, tendo em vista a possibilidade de servirem como alternativas aos agentes antimicrobianos promotores de crescimento utilizados em potencial em dietas para leitões.

$\mathrm{O}$ tratamento com antimicrobiano resultou em maior peso relativo dos rins $(\mathrm{P}<0,01)$, quando comparado à média dos tratamentos com extrato de cravo, extrato de orégano e extrato de cravo + extrato de orégano. Utiyama et al. (2006), estudando o efeito de antimicrobianos, probióticos, prebióticos e extratos vegetais sobre a morfometria dos 
Tabela 4 - Médias dos pesos relativos (\% do PV) dos órgãos, do comprimento, do comprimento relativo e da relação peso:comprimento do intestino delgado de leitões tratados com extratos vegetais em comparação a antimicrobianos

Table 4 - Average of relative weight (\% of live weight) of organs, length of small intestine, relative length of small intestine and weight:length ratio of small intestine according to the treatments

\begin{tabular}{|c|c|c|c|c|c|c|c|}
\hline \multirow{2}{*}{$\begin{array}{l}\text { Órgãos } \\
\text { Organs }\end{array}$} & \multicolumn{5}{|c|}{$\begin{array}{c}\text { Tratamento } \\
\text { Treatment }\end{array}$} & \multirow[t]{2}{*}{$\operatorname{Pr}>\mathrm{F}$} & \multirow[t]{2}{*}{$\mathrm{CV}^{2}(\%)$} \\
\hline & $\begin{array}{c}\text { C } \\
\text { Control }\end{array}$ & A & $\mathrm{Ec}$ & Eo & $\mathrm{Ec}+\mathrm{Eo}$ & & \\
\hline Estômago (\%) (Stomach) & 0,74 & 0,79 & 0,85 & 0,69 & 0,68 & 0,23 & 15,93 \\
\hline Pâncreas (\%) (Pancreas) & 0,21 & 0,18 & 0,23 & 0,20 & 0,20 & 0,96 & 16,26 \\
\hline Fígado $(\%)$ (Liver) & 2,81 & 2,42 & 2,56 & 2,49 & 2,50 & 0,57 & 17,44 \\
\hline Vesícula biliar (\%) (Gall-bladder) & 0,10 & 0,07 & 0,10 & 0,09 & 0,09 & 0,84 & 35,10 \\
\hline Intestino delgado (\%) (Small intestine) & 4,86 & 4,56 & 5,53 & 5,17 & 5,33 & 0,78 & 13,74 \\
\hline Intestino grosso (\%) (Large intestine) & 2,32 & 2,28 & 2,41 & 2,39 & 2,29 & 0,86 & 16,91 \\
\hline Ceco $(\%)$ (Caecum) & 0,23 & 0,26 & 0,23 & 0,25 & 0,24 & 0,44 & 19,00 \\
\hline Cólon (\%) (Colon) & 1,69 & 1,80 & 1,99 & 1,96 & 1,84 & 0,80 & 17,35 \\
\hline Pulmões (\%) (Lungs) & 1,00 & 1,04 & 1,09 & 1,04 & 1,13 & 0,42 & 14,79 \\
\hline Coração (\%) (Heart) & 0,51 & 0,52 & 0,48 & 0,49 & 0,55 & 0,25 & 18,08 \\
\hline $\operatorname{Rins}^{3}(\%)$ (Kidneys) & 0,50 & 0,58 & 0,54 & 0,48 & 0,49 & 0,01 & 8,17 \\
\hline Baço $(\%)$ (Spleen) & 0,15 & 0,18 & 0,19 & 0,13 & 0,16 & 0,10 & 19,58 \\
\hline Comprimento do ID (m) (Small intestine length) & 14,65 & 16,08 & 14,96 & 14,89 & 15,41 & 0,92 & 5,99 \\
\hline Comp. relativo ID (m/kg PV) (Small intestine relative length) & 0,10 & 0,09 & 0,11 & 0,10 & 0,10 & 0,36 & 15,49 \\
\hline Relação peso:comp. ID ( $\mathrm{g} / \mathrm{m})$ (Weight:length ratio of small intestine) & 51,43 & 52,84 & 50,88 & 53,48 & 55,55 & 0,75 & 10,65 \\
\hline
\end{tabular}

${ }^{1} \mathrm{C}$ - controle (control), Ec - 420 ppm de extrato de cravo (420 ppm of clove extract), Eo - 420 ppm de extrato de orégano (420 ppm of oregan extract), Ec + Eo $420 \mathrm{ppm}$ de extrato de cravo + extrato de orégano (420 ppm of clove and oregano extracts).

2 Coeficiente de variação (Coefficient of variation).

${ }^{3}$ Contraste significativo: A X média de Ec, Eo e Ec + Eo $(P<0,01)$.

${ }^{3}$ Contrast significantly different: $A X$ mean of $E c$, Eo and $E C+E O(P<0.01)$.

órgãos de leitões em recria, também observaram maior peso relativo dos rins dos animais que receberam antimicrobianos na dieta (Tabela 4).

Apesar de não-significativa $(\mathrm{P}>0,05)$, houve, numericamente, maior relação peso:comprimento (densidade) do intestino delgado nos animais do tratamento extrato de cravo + extrato de orégano. O possível aumento da densidade do intestino delgado proporcionado pela combinação de extratos vegetais pode ter sido conseqüência do elevado consumo de alimento pelos leitões, visto que a ingestão de alimentos é o principal fator que influencia a massa intestinal (Burrin et al., 2001).

Os animais tratados com antimicrobiano apresentaram, numericamente, o menor peso relativo dos intestinos delgado e grosso vazios. Um dos modos de ação dos agentes antimicrobianos está relacionado à redução na quantidade de microrganismos produtores de toxinas aderidos ao epitélio intestinal e, conseqüentemente, à redução da espessura da parede intestinal (Anderson et al., 1999). Esse efeito proporciona economia de nutrientes pelo animal para manutenção dos tecidos do trato gastrintestinal (Lima, 1999), favorecendo seu desempenho. Esse modo de ação sobre os microrganismos presentes no intestino de leitões pode proporcionar menor fermentação microbiana e diminuir a produção de ácidos graxos voláteis que fornecem boa parte da energia exigida para o desenvolvimento dos enterócitos (Lin \& Visek, 1991). No cólon, até 60-70\% da energia utili- zada pelas células epiteliais provém dos produtos da fermentação microbiana (Cummings \& Macfarlane, 1991). Assim, a menor produção de ácidos graxos voláteis pode acarretar menor taxa de replicação celular no epitélio intestinal de leitões que recebem antimicrobianos na dieta, ocasionando redução dos pesos relativos dos intestinos delgado e grosso.

Os animais do tratamento extrato de cravo apresentaram, numericamente, o maior peso relativo do pâncreas, o que está de acordo com os resultados obtidos em outros trabalhos (Lee et al., 2003; Hernández et al., 2004; Utiyama et al., 2006; Oetting et al., 2006) nos quais o maior peso relativo do pâncreas foi observado nos animais que receberam extratos vegetais na dieta. Adicionalmente, tem-se observado em ratos que extratos vegetais podem aumentar a secreção de saliva, suco gástrico, suco pancreático, sais biliares e enzimas do intestino delgado (Sambaiah \& Srinivasan, 1991; Platel \& Srinivasan, 1996; Wang \& Bourne, 1998). Contudo, são poucos os estudos realizados com extratos vegetais para avaliação da morfometria dos órgãos de suínos e os resultados são pouco conclusivos.

\section{Conclusões}

Os agentes antimicrobianos, em uma combinação de 75 ppm de colistina e 75 ppm de tiamulina, proporcionaram os melhores desempenhos de leitões em fase de creche. Os 
extratos vegetais de cravo e orégano, individualmente, apresentaram efeitos ligeiramente redutores sobre o desempenho dos animais. Por outro lado, a combinação dos extratos de cravo e orégano (105 ppm de óleo essencial de cravo + 105 ppm de eugenol e 105 ppm de óleo essencial de orégano +105 ppm de carvacrol) promoveu desempenho muito próximo ao obtido com os antimicrobianos, demonstrando ser uma alternativa promissora como promotor de crescimento de leitões recém-desmamados.

\section{Literatura Citada}

ANDERSON, D.B.; McCRACKEN, V.J.; AMINOV, R.I. et al. Gut microbiology and growth-promoting antibiotics in swine. Pigs News Information, v.20, p.115-122, 1999.

BOTSOGLOU, N.A.; FLOROU-PANERI, P.; CHRISTAKI, E. et al. Performance of rabbits and oxidative stability of muscle tissues as affected by dietary supplementation with oregano essential oil. Archives of Animal Nutrition, v.58, n.3, p.209-218, 2004. BOTSOGLOU, N.A.; FLOROU-PANERI, P.; CHRISTAKI, E. et al. Effect of dietary oregano essential oil on performance of chickens and on iron-induced lipid oxidation of breast, thigh and abdominal fat tissues. British Poultry Science, v.43, p.223-230, 2002 .

BRUGALI, I. Alimentação alternativa: a utilização de fitoterápicos ou nutracêuticos como moduladores da imunidade e desempenho animal. In: SIMPÓSIO SOBRE MANEJO E NUTRIÇÃO DE AVES E SUÍNOS, 2003, Campinas. Anais... Campinas: Colégio Brasileiro de Nutrição Animal, 2003. p.167-182.

BURRIN, D.G.; STOLL, B.; van GOUDOEVER, J.B. et al. Nutrition requirements for intestinal growth and metabolism in the developing pig. In: LINDBERG, J.E.; OGLE, B. (Eds.). Digestive physiology of pigs. Wallingford: CABI Publishing, 2001. p.75-78.

CUMMINGS, J.H.; MACFARLANE, G.T. The control and consequences of bacterial fermentation in the human colon. Journal of Applied Bacteriology, v.70, p.443-459, 1991.

FOOD AGRICULTURE ORGANIZATION - FAO. Disponível em: <http://www.fao.org> Acesso em: 06/10/2005.

HERMANN, J.R.; HONEYMAN, M.S.; ZIMMERMAN, J.J. et al. Effect of dietary Echinacea purpurea on viremia and performance in porcine reproductive and respiratory syndrome virus-infected nursery pigs. Journal of Animal Science, v.81, p.2139-2144, 2003.

HERNÁNDEZ, F.; MADRID, J.; GARCIA, V. et al. Influence of two plant extracts on broilers performance, digestibility, and digestive organ size. Poultry Science, v.83, p.169-174, 2004.

JONG, E.U.; LEBOUTE, E.M.; CIOCCA, M.L. et al. Uso de avoparcina e virginiamicina como promotores de crescimento em rações de frangos de corte. 2. Efeito sobre a flora intestinal e estrutura física do intestino. Revista Brasileira de Zootecnia, v.14, p.536-542, 1985.

KAMEL, C. A novel look at a classic approach of plant extracts. Feed Mix - The International Journal on Feed, Nutrition and Technology, v.9, n.6, p.19-24, 2000. (Special number).

LEE, K.W.; EVERTS, H.; KAPPERT, H.J. et al. Effects of dietary essential oil components on growth performance, digestive enzymes and lipid metabolism in female broiler chickens. British Poultry Science, v.44, n.3, p.450-457, 2003.
LIMA, G.J.M.M. Uso de aditivos na produção de suínos. In: SIMPÓSIO SOBRE AS IMPLICAÇÕES SÓCIO-ECONÔMICAS DO USO DE ADITIVOS NA PRODUÇÃO ANIMAL, 1999, Piracicaba. Anais... Piracicaba: Universidade Metodista de Piracicaba, 1999. p.51-68.

LIN, H.C.; VISEK, W.J. Colon mucosal cell damage by ammonia in rats. Journal of Nutrition, v.121, p.887-893, 1991.

MELLOR, S. Herbs and spices promote health and growth. Pig Progress, v.16, n.4, p.18-21, 2000.

MENTEN, J.F.M. Aditivos alternativos na produção de aves: probióticos e prebióticos. In: REUNIÃO DA SOCIEDADE BRASILEIRA DE ZOOTECNIA, 38., 2001, Piracicaba. Anais... Piracicaba: Sociedade Brasileira de Zootecnia, 2001. p.141-157.

MENTEN, J.F.M. Eficácia, efeito sinérgico e modo de ação de agentes antimicrobianos como promotores do crescimento de suínos. Piracicaba: Escola Superior de Agricultura "Luiz de Queiroz", 1995. 106p. Tese (Livre Docência em Nutrição de Suínos) - Escola Superior de Agricultura "Luiz de Queiroz"- Universidade de São Paulo, 1995.

MILLER, E.R.; ULLREY, D.E.; LEWIS, A.J. Swine nutrition. Stoneham: Butterworth-Heinemann, 1991.673p.

OETTING, L.L.; UTIYAMA, C.E.; GIANI, P.A. et al. Efeitos de extratos vegetais e antimicrobianos sobre a digestibilidade aparente, o desempenho, a morfometria dos órgãos e a histologia intestinal de leitões recém-desmamados. Revista Brasileira de Zootecnia, v. 35, n. 4, p.1389-1397, 2006.

PARTANEN, K. Uso de aditivos na produção de suínos. In: SIMPÓSIO SOBRE MANEJO E NUTRIÇÃO DE AVES E SUÍNOS E TECNOLOGIA NA PRODUÇÃO DE RAÇÕES, 2002, Campinas. Anais... Campinas: Colégio Brasileiro de Nutrição Animal, 2002. p.45-62.

PLATEL, K.; SRINIVASAN, K. Influence of dietary spices or their active principles on digestive enzymes of small intestinal mucosa in rats. International Journal Food Sciences and Nutrition, v.47, p.55-59, 1996.

ROSTAGNO, H.S.; ALBINO, L.F.T.; DONZELE, J.L. et al. Tabelas brasileiras para aves e suínos: composição de alimentos e exigências nutricionais. 2.ed. Viçosa, MG: Universidade Federal de Viçosa, 2005. 186p.

SAMBAIAH, K.; SRINIVASAN, K. Secretion and composition of bile in rats fed diets containing spices. Journal of Food Science and Technology, v.28, p.35-38, 1991.

STATISTICAL ANALYSIS SYSTEM - SAS. SAS user's guide: statistics. Carry, 2001. 155p.

TAVARES, W. Manual de antibióticos e quimioterápicos antiinfecciosos. Rio de Janeiro: Atheneu, 1990. 515p.

UTIYAMA, C.E.; OETTING, L.L.; GIANI, P.A. et al. Efeitos de antimicrobianos, prebióticos, probióticos e extratos vegetais sobre a microbiota intestinal, a frequiência de diarréia e o desempenho de leitões recém-desmamados. Revista Brasileira de Zootecnia, v.35, n.6, p.2359-2367, 2006.

WANG, R.; LI, D.; BOURNE, S. Can 2000 years of herbal medicine history help us solve problems in UK. Anais... Nottingham: Alltech, 1998. p.168-184.

ZUANON, J.A.S.; FONSECA, J.B.; ROSTAGNO, H.S. et al. Efeito de promotores de crescimento sobre o desenvolvimento de frangos de corte. Revista Brasileira de Zootecnia, v.27, p.999-1005, 1998. 